\title{
General Intelligence as a Domain-Specific Adaptation
}

\author{
Satoshi Kanazawa \\ London School of Economics and Political Science
}

\begin{abstract}
General intelligence $(g)$ poses a problem for evolutionary psychology's modular view of the human brain. The author advances a new evolutionary psychological theory of the evolution of general intelligence and argues that general intelligence evolved as a domain-specific adaptation for the originally limited sphere of evolutionary novelty in the ancestral environment. It has accidentally become universally important merely because we now live in an evolutionarily novel world. The available data seem to support the author's contention that intelligent people can solve problems better than less intelligent people only if the problems are evolutionarily novel, and they have no advantage in solving evolutionarily familiar problems. This perspective can also solve some empirical anomalies, such as the "central theoretical problem of human sociobiology" (D. R. Vining, 1986, p. 167) and the geographic distribution of general intelligence throughout the world.
\end{abstract}

The $g$ factor is actually a biologically based variable, which, like other biological functions in the human species, is necessarily a product of the evolutionary process. (Jensen, 1998, p. xii)

The existence of the $g$ factor (the "general intelligence" factor) in psychometrics appears to contradict the strong modularity view of the mind. (Miller, 2000, p. 42)

Larry King: What, Professor, puzzles you the most? What do you think about the most?

Stephen Hawking: Women.

Larry King: Welcome aboard.

—Larry King Live Weekend (December 25, 1999)

One of the basic tenets of evolutionary psychology (Barkow, Cosmides, \& Tooby, 1992) is that the human mind consists of distinct evolved psychological mechanisms. An evolved psychological mechanism is an information-processing procedure or "decision rule," which evolution by natural and sexual selection has equipped humans to possess in order to solve adaptive problems (problems of survival and reproduction); it is roughly synonymous with an adaptation or a module, although adaptations include physical products of evolution outside of the brain (such as arms and legs). There is a distinct psychological mechanism or mechanisms for each adaptive problem; a psychological mechanism is designed to solve a specific adaptive problem in a specific domain of life (Geary \& Huffman, 2002, pp. 681-690).

Therein lies the problem for evolutionary psychology posed by the concept and the ubiquity of general intelligence (the $g$ factor),

I thank Garth J. O. Fletcher for disagreeing with me, thereby motivating me to write this article, and Rosemary L. Hopcroft, Christine Horne, W. Jake Jacobs, Richard Lynn, Geoffrey F. Miller, and J. Philippe Rushton for their comments on drafts.

Correspondence concerning this article should be addressed to Satoshi Kanazawa, Interdisciplinary Institute of Management, London School of Economics and Political Science, Houghton Street, London WC2A 2AE, United Kingdom. E-mail: S.Kanazawa@1se.ac.uk which Miller's (2000) quote above highlights. Nobody denies the existence and importance of the $g$, and as its name implies, its importance is not limited to one or a few specific areas of life. General intelligence is important for individual performance in virtually every sphere of modern life (Gottfredson, 1997; Herrnstein \& Murray, 1994). If the human mind consists of domainspecific evolved psychological mechanisms, how then does evolutionary psychology explain the existence and importance of $g$ ?

In this article, I present a new theory of the evolution of general intelligence, which reconciles the universal importance of $g$ noted by psychometricians with the modular view of the mind proposed by evolutionary psychologists. I argue that what we now call general intelligence evolved as a domain-specific adaptation in the sphere of evolutionary novelty and was therefore not general at all in its evolutionary origin. Its importance has accidentally become general simply because many elements in the natural (physical) environment are evolutionarily novel, even though much of the social (interpersonal) environment has remained the same. My theory of the evolution of human intelligence suggests novel predictions for the importance (and unimportance) of $g$ and solves some empirical puzzles in evolutionary psychology and psychometrics.

\section{Unraveling the Enigma of Human Intelligence}

Co-inventors of modern evolutionary psychology, Leda Cosmides and John Tooby, have already attempted to explain the evolution of general intelligence from the evolutionary psychological perspective. They first make a distinction between dedicated intelligence and improvisational intelligence. "Dedicated intelligence refers to the ability of a computational system to solve a predefined, target set of problems. Improvisational intelligence refers to the ability of a computational system to improvise solutions to novel problems" (Cosmides \& Tooby, 2002, p. 146). In essence, what they call dedicated intelligence here is what they and other evolutionary psychologists call a domain-specific evolved psychological mechanism, and what they call improvisational intelligence here is what psychometricians call general intelligence or $g$. 
While their definitions are very clear, their explanation for how general intelligence evolved is not quite as explicit. They argue that general intelligence evolved as an emergent property of a collection of psychological mechanisms. "Cognitive specializations, each narrow in their domain of application, can be bundled together in a way [italics added] that widens the range of inputs or domains that can be successfully handled" (Cosmides \& Tooby, 2002, pp. 177-178). Exactly how the domain-specific psychological mechanisms can be bundled together to produce domaingeneral intelligence is not clear, however.

Large amounts of knowledge are embodied in intelligent, domainspecific inference systems, but these systems were designed to be triggered by stimuli in the world. This knowledge could be unlocked and used for many purposes, however, if a way could be found [italics added] to activate these systems in the absence of the triggering stimuli-that is, if the inference system could be activated by imagining a stimulus situation that is not actually occurring: a counterfactual. (Cosmides \& Tooby, 2002, p. 182)

They do not explicate how this way could be found.

The left panel of Figure 1 presents the schematic representation of my interpretation of Cosmides and Tooby's (2002) view of general intelligence. The inner circle represents the human brain. In accordance with the prevailing assumption of evolutionary psychology, the brain consists of domain-specific evolved psychological mechanisms, such as the cheater detection mechanism (Cosmides, 1989), the language acquisition device (Pinker, 1994), and discriminative parental solicitude (Daly \& Wilson, 1987). There are a large number of other evolved psychological mechanisms that evolutionary psychologists have discovered, and there are probably even more that they have not yet catalogued. Each psychological mechanism can solve adaptive problems in its own narrow domain but nowhere else; that is why Cosmides and Tooby call it dedicated intelligence. The cheater detection mechanism can only help actors decide who has violated social contract. It does not help them acquire their native language or decide which of their children into which to invest more or fewer resources.

According to Cosmides and Tooby (2002), general intelligence emerges as a function of the bundle of evolved psychological mechanisms. I designate this bundle as an outer circle encompassing all of the evolved psychological mechanisms. Its domain of application covers the sum total of all the domains of the psychological mechanisms that form its foundation. It is therefore domain general.

Apart from the absence in their writing of exactly how general intelligence evolves, one of the most unsatisfying aspects of their evolutionary psychological theory of the evolution of general intelligence is that it is not an adaptation selected for by evolutionary forces. It is instead an exaptation, which first appears as an emergent property of all the adaptations (psychological mechanisms) and then acquires its function later (Buss, Haselton, Shackelford, Bleske, \& Wakefield, 1998). An exaptation is "a feature, now useful to an organism, that did not arise as an adaptation for its present role, but was subsequently co-opted for its current function" (Gould, 1991, p. 43). Somehow, it seems unlikely to me that something as important and crucial as general intelligence was not selected for and was not designed by evolution for its current functions.

\section{General Intelligence as a Domain-Specific Adaptation}

I completely share Cosmides and Tooby's (2002) view on the evolution of dedicated intelligences. There were recurring adaptive problems in the environment of evolutionary adaptedness (EEA),
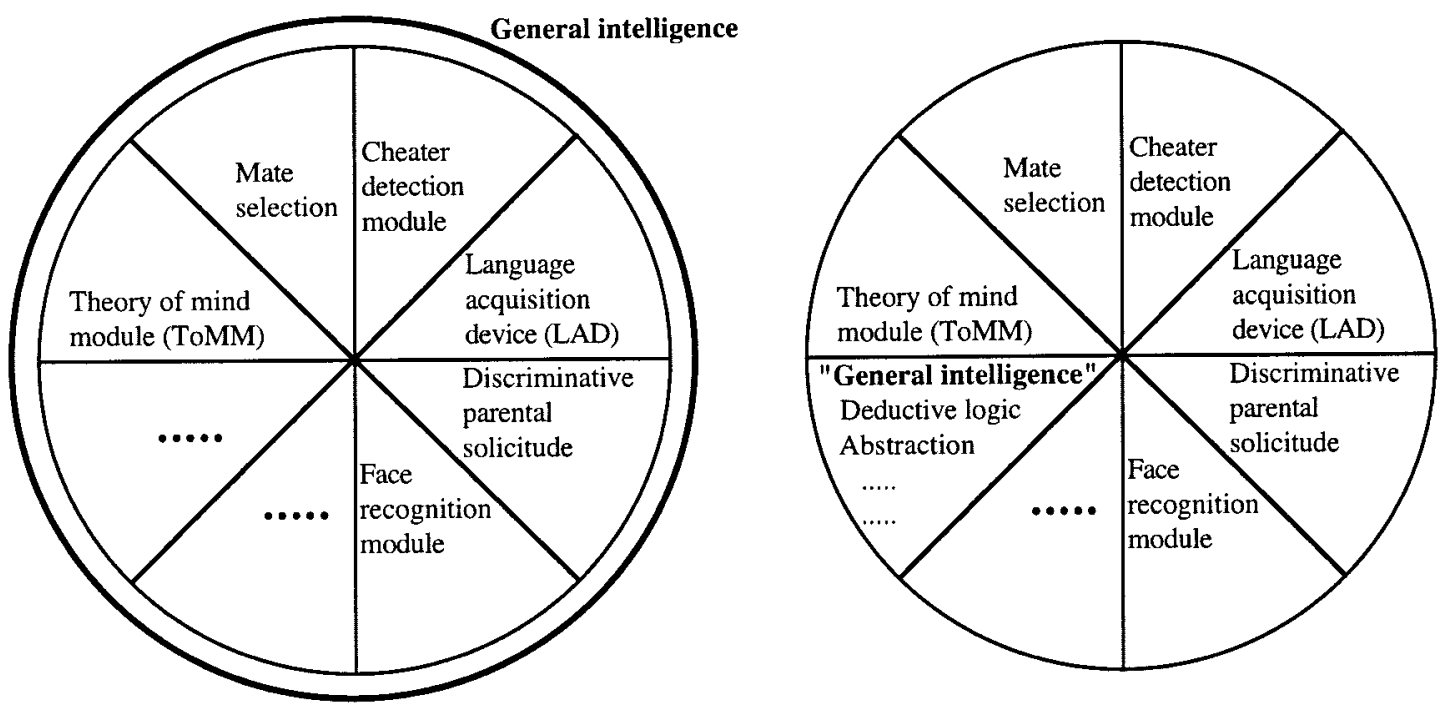

Figure 1. Two alternative explanations for the evolution of general intelligence. Left: Cosmides and Tooby's (2002) view. Right: The view proposed in the current article. The inner circle with the solid line in both panels represents the human brain, consisting of distinct evolved psychological mechanisms. There can be a large number of such psychological mechanisms, represented by the empty cells with $\bullet \bullet \bullet \bullet$. The outer circle with the bold line in the left panel represents the emergent general intelligence in Cosmides and Tooby's theory. Note that in the theory presented in this article, represented by the right panel, general intelligence is just one of the many evolved psychological mechanisms. 
the solution of which enhanced individuals' inclusive fitness. Evolution by natural and sexual selection has therefore equipped humans (and other organisms) with domain-specific psychological mechanisms to solve these problems in given domains of life (Geary \& Huffman, 2002, pp. 681-690). This is why we have an innate ability to be sensitive to potential cheaters in social exchange (Cosmides, 1989; Yamagishi, Tanida, Mashima, Shimoma, \& Kanazawa, 2003), why all developmentally normal human children can acquire any natural human language with relative ease (Pinker, 1994), and why parents can unconsciously favor some offspring whose reproductive prospect is greater at the cost of others whose reproductive prospect is gloomier (Daly \& Wilson, 1987). I agree with Cosmides and Tooby's multimodular view of the human mind and the existence of every single module, except for one.

The Pleistocene epoch (about 1.6 million to 10,000 years ago), during which humans evolved, was a period of extraordinary constancy and continuity. Our ancestors were hunter-gatherers on the African savanna all their lives. Their grandparents were hunter-gatherers on the African savanna all their lives. Their parents were hunter-gatherers on the African savanna all their lives. Their children were hunter-gatherers on the African savanna all their lives. Their grandchildren were hunter-gatherers on the African savanna all their lives. It is against this backdrop of extreme stability that all of our adaptations evolved because, for instance, those who had a taste for sweet and fatty food during the Pleistocene lived longer and reproduced more successfully, by acquiring more calories (Barash, 1982, pp. 144-147), or those who preferred a certain landscape for their habitat lived longer and reproduced more successfully, by avoiding potential predators in hiding (Orians \& Heerwagen, 1992). The evolution of psychological mechanisms assumes a stable environment; solutions cannot evolve in the form of psychological mechanisms if the problems keep changing. The fact that we have so many evolved psychological mechanisms is testimony to extraordinary stability of the EEA.

Because adaptive problems in the EEA remained more or less the same generation after generation, our evolved psychological mechanisms were sufficient to solve them. In a sense, our ancestors did not have to think in the EEA. They didn't have to think, for instance, what was good to eat. All they had to do was to eat and keep eating what tasted good to them (sweet and fatty foods that contained high calories), and they lived long and remained healthy. ${ }^{1}$ People who preferred the wrong kind of food died off before leaving too many offspring, and we did not inherit our psychological mechanisms from them. All the adaptive problems were anticipated by our evolved psychological mechanisms, which then provided their solutions (Geary, 2002).

Even in the EEA, however, there were a few novel, nonrecurrent problems on occasion. ${ }^{2}$ By definition, we do not have prepared solutions in the form of evolved psychological mechanisms for novel, nonrecurrent problems. As a result, many of our potential ancestors undoubtedly died because they could not solve these novel problems. Novel, nonrecurrent problems require thinking and reasoning in order to solve them. Such novel, nonrecurrent problems may have included the following examples:

1. The lightning has struck the tree near the camp and set it on fire. The fire is now spreading to the dry underbrush.
What should I do? How could I stop the spread of the fire? How could I and my family escape it? (Since lightning never strikes the same place twice, this is guaranteed to be a nonrecurrent problem.)

2. We are in the middle of the severest drought in a hundred years. Nuts and berries at our normal places of gathering, which are usually plentiful, are not growing at all, and animals are scarce as well. We are running out of food because none of our normal sources of food are working. What else can we eat? What else is safe to eat? How else can we procure food?

3. A flash flood has caused the river to swell to several times its normal width, and I am trapped on one side of it while my entire band is on the other side. It is imperative that I rejoin them soon. How could I cross the rapid river? Should I walk across it? Or should I construct some sort of buoyant vehicle to use to get across it? If so, what kind of material should I use? Wood? Stones?

Solutions to these and other novel, nonrecurrent problems require improvisational intelligence, the ability to reason deductively or inductively, think abstractly, use analogies, synthesize information, and apply it to new domains. Anyone whose brain consists entirely of dedicated intelligences in the form of domain-specific evolved psychological mechanisms cannot solve novel, nonrecurrent problems, and in the worst case scenario, they may die due to their inability to solve them. It therefore follows that, if novel, nonrecurrent problems happened frequently enough in the EEA (a different problem each time), then any genetic mutation that equips its carrier to think and reason would be selected for and could evolve as a domain-specific adaptation in order to solve novel, nonrecurrent problems. Novelty becomes its domain of application; general intelligence evolves as a dedicated intelligence for the sphere of evolutionary novelty. In my perspective, "general intelligence" is nothing but another domain-specific evolved psychological mechanism (see the right panel of Figure 1).

I hasten to add that the extreme constancy and continuity of the EEA mean that these novel, nonrecurrent problems did not happen very frequently, and dedicated intelligence was sufficient to solve the vast majority of problems. In other words, in clear contrast to modern life, what psychometricians today call general intelligence

\footnotetext{
${ }^{1}$ Despite the popular (but misleading) phrase "survival of the fittest," which was coined not by Charles Darwin but by Herbert Spencer, reproductive success, not survival, is the currency, the "bottom line," of evolutionary forces. Survival to sexual maturity is a necessary, but not sufficient, condition for reproductive success via direct reproduction (producing own offspring). Of course, organisms can also attain reproductive success (inclusive fitness) indirectly via kin selection (through offspring of genetic relatives; Hamilton, 1964).

${ }^{2}$ If the problem was novel but recurring from then on (which thus ceases to be novel), then there would eventually be an evolved psychological mechanism specifically to deal with it. General intelligence would not be necessary to solve such problems.
} 
or the $g$ factor was not very important in solving problems in the EEA. But it was sufficiently important to have evolved. ${ }^{3}$

From my perspective, $g$ has become so universally important in modern life (Gottfredson, 1997; Herrnstein \& Murray, 1994) precisely because it is entirely evolutionarily novel. One quick exercise should be sufficient to convince you of this simple historical fact. Look around and note everything around you. How many things do you see that existed 10,000 years ago, at the end of the Pleistocene? I would venture to guess that the answer is at most four: men, women, boys, and girls. If you are outside, you might be tempted to count things like trees, flowers, mountains, and rivers, but unless you happen to be in sub-Saharan Africa, these are not the same trees, flowers, mountains, and rivers that our ancestors encountered. The point is that virtually everything you see around you today in your natural environment (books, computers, telephones, televisions, automobiles, etc.) is evolutionarily novel, even though much of your social environment, containing other people, has remained the same. Our evolved psychological mechanisms, adapted to the EEA, cannot recognize many of the physical objects around us today (Kanazawa, 2002, 2004), and our evolved psychological mechanisms are therefore useless in solving most of our daily problems, except when they deal with other people. Even in this area, however, evolutionarily novel inventions such as effective contraception, socially imposed monogamy, and criminal laws regarding the age of consent foil the operations of our evolved psychological mechanisms today. General intelligence has become so pervasively important in our lives only because we have created and live in an evolutionarily novel world.

\section{Empirical Implications for Alternative Theories}

Cosmides and Tooby's (2002) theory of the evolution of general intelligence as an emergent exaptation and my theory of it as a domain-specific adaptation entail divergent empirical implications. Because Cosmides and Tooby argue that general intelligence emerges from, and is built on the foundation of, the "bundle" of evolved psychological mechanisms, their theory implies a positive correlation between the performance of general intelligence and that of any of the evolved psychological mechanisms at its foundation.

Improvisational intelligence does not appear to be an autonomous ability, disconnected from the rest of the architecture and not relying on any other computational or information resources. On the contrary. Not only does it depend on a base of dedicated intelligences but it also must be supplied with a dense accumulation of information relevant to the situation being faced. (Cosmides \& Tooby, 2002, p. 179)

In other words, Cosmides and Tooby's theory would predict that individuals with high IQs (as a measure of $g$ ) would also have greater ability to detect cheaters in exchange situations, acquire native language, select better mates, infer others' intentions correctly, and so on. Chiappe and MacDonald (2003) offer a similar view in their account of the evolution of domain-general intelligence, and Geary (2002) similarly explains the emergence of modern academic competence from the foundation of evolved psychological mechanisms.

In sharp contrast, my theory would predict a complete independence of $g$ from all the other evolved psychological mechanisms in the brain. I would not expect those who are good at recognizing faces to be better at allocating parental resources among their children. Similarly, I would not expect individuals with high IQs to be necessarily better at either, or at any other, evolutionarily relevant task. The exchange between Larry King and Stephen Hawking quoted above, in which Hawking responds (largely, although probably not entirely, in jest) that what puzzles him most are women, captures the essence of my argument. My theory would predict that the Lucasian Professor of Mathematics at the University of Cambridge (a post once held by Isaac Newton), who is putatively the most intelligent person in the United Kingdom today and can figure out the origin and the destiny of the universe, has no particular advantage in evolutionarily familiar domains of life such as mating, over someone like Larry King, who has only a high school education and, incidentally, has had six wives.

In general, my theory suggests two complementary empirical hypotheses.

1. Intelligent (high-g) individuals are better able to solve problems than less intelligent (low- $g$ ) individuals, only if the problems are evolutionarily novel.

2. Intelligent (high- $g$ ) individuals are no more able to solve problems than less intelligent (low- $g$ ) individuals, if the problems existed in the EEA and are thus evolutionarily familiar.

A large number of empirical studies already unambiguously demonstrates the overwhelming importance of $g$ in the (evolutionarily novel) contemporary society. I will not summarize these studies here; see Gordon (1997), Gottfredson (1997), Herrnstein and Murray (1994), Jensen (1998, pp. 270-305), and Locurto (1997, pp. 80-87) for reviews of this literature. I will instead focus on the few evolutionarily familiar situations where $g$ does not predict success, in order to support my theory of the evolution of general intelligence as a domain-specific adaptation.

\section{General Intelligence and Cheater Detection}

In a series of experiments, Cosmides (1989) demonstrates that, while humans are notoriously inept at solving the Wason selection tasks when they are posed as an abstract logical problem, they are much better at solving them when they are expressed as a problem of honoring or violating social contract, even though the problem has the same logical structure either way. For instance, most people have difficulty comprehending that "If $\mathrm{P}$, then Q" does not logically entail "If $\mathrm{Q}$, then $\mathrm{P}$ " or "If not-P, then not-Q," even though they have no difficulty understanding that just because one must be at least 21 to drink alcohol doesn't mean that adults in a bar must always drink alcohol or anyone drinking Pepsi is necessarily a minor. Cosmides argues that this is because humans possess a cheater detection module, which prevents us from being taken advantage of in social exchange. The cheater detection

\footnotetext{
${ }^{3}$ Baum (1994, pp. 80-82) argues from the behaviorist perspective that a capacity for novel behavior ("creativity") can be selected for on an ontogenetic time scale by reinforcement history, just as I argue from the evolutionary psychological perspective that a capacity for solving novel problems can be selected for on a phylogenetic time scale by evolutionary history.
} 
module evolved, because social exchange was a recurrent feature of the EEA, and our ancestors who were watchful for potential defectors did better than those who were often taken advantage of. The same module does not help us solve abstract logical problems because they did not exist in the EEA.

Unlike cheater detection in social exchange, abstract logical problems are evolutionarily novel. Thus my theory would predict that high- $g$ individuals would perform better than low- $g$ individuals at solving the Wason selection tasks when stated as abstract logical problems. In contrast, since cheater detection is evolutionarily familiar and is handled by a different module than "general intelligence" (see the left panel of Figure 1), high- $g$ individuals should do no better than low- $g$ individuals at solving the Wason selection tasks when stated as social contracts. Cosmides and Tooby (2002), on the other hand, would predict a correlation between these two tasks: Those who perform better at solving the Wason selection tasks when stated as abstract logical problems should also do better when the same problems are stated as social contracts.

The experimental evidence has so far been equivocal. On the one hand, in support of my theory, Stanovich and West (2000) demonstrate that, when the problem is presented in its abstract logical (nondeontic) form, those who answer it correctly have a significantly higher general intelligence (measured by the Scholastic Aptitude Test) than those who answer it incorrectly $(1,270$ vs. $1,187, p<.01, d=.815$ ). However, when the same problem is presented in the cheater-detection (deontic) form, the effect size of general intelligence either becomes, while still statistically significant, less than half in one test (1,206 vs. 1,170, $p<.05, d=$ $.347)$ or becomes altogether statistically nonsignificant in another $(1,198$ vs. $1,189, n s, d=.088)$. Stanovich and West's (2000) data thus demonstrate that high- $g$ individuals have little or no advantage over low- $g$ individuals in detecting cheaters. On the other hand, DeShon, Smith, Chan, and Schmitt (1998) show that the White-Black difference in performance on the Wason selection tasks remains the same whether they are stated as abstract logical problems or as social contracts.

\section{General Intelligence, Mating, and Parenting}

Mating and parenting are eminently evolutionarily familiar domains of life. As I point out above, men, women, boys, and girls are probably the only things that our stone-age brain truly recognizes. Despite the cumbersome interventions of modern inventions (condoms, sperm banks, Playboy), we still mate, pretty much the same way as our ancestors did 3 million years ago, and we still have children as they did then. My theory therefore predicts that general intelligence has no effect on individuals' likelihood of mating and parenting, whereas Cosmides and Tooby (2002) would predict that the mating and parenting modules of more intelligent individuals would function more efficiently than those of less intelligent individuals.

Herrnstein and Murray (1994) compile a comprehensive list of life outcomes that are affected by $g$. From schooling to employment to crime and welfare dependency to civility and citizenship, not only do more intelligent individuals achieve more desirable outcomes, but $g$ almost always has a linear relationship with the desirability of the outcome.
Marriage and parenting are among the very few exceptions to this pattern in Herrnstein and Murray's (1994) comprehensive review of American life, however. In fact, "very bright" individuals (with IQs above 125, at or above the 95th percentile of the IQ distribution) are the least likely to marry of all the cognitive classes. Only $67 \%$ of these "very bright" White Americans marry before the age of 30 , whereas between $72 \%$ and $81 \%$ of those in other cognitive classes marry before 30 (Herrnstein \& Murray, 1994, pp. 168-172). The mean age of first marriage among the very bright Whites is 25.4, whereas that among the "very dull" (with IQs below 75) is 21.3 and that among the "dull" (with IQs between 75 and 90) is 21.5 .

General intelligence does not seem to confer advantage to marriage. Two caveats are in order, however. First, being unmarried is not always the same as unmated. Second, these results, and those that follow, do not necessarily mean that highly intelligent individuals are less efficacious in achieving their goals because very bright people may not want to get married or have children. ${ }^{4}$ However, it does mean that highly intelligent individuals are less efficacious in pursuing the Darwinian goal of reproductive success, for which human beings (as well as all other living organisms) are designed.

The pattern appears to be similar when it comes to parenting. General intelligence does not confer advantage in giving birth to healthy babies. Five percent of White babies born to "very bright" mothers suffer from low birth weight, compared to $1.6 \%$ of those born to merely "bright" mothers (with IQs between 110 and 125) and $3.2 \%$ of those born to "normal" (with IQs between 90 and 110) mothers. Only those born to "dull" mothers (7.2\%) and "very dull" mothers (5.7\%) fare worse (Herrnstein \& Murray, 1994, pp. 213-218).

The lack of IQ advantage continues later in childhood. "Very bright" mothers are more likely to have children who are behind in motor and social development or have the worst behavioral problems. Ten percent of children born to "very bright" White mothers are in the bottom decile of the motor and social development index, compared to $5 \%$ of those born to "bright" mothers and $6 \%$ of those born to "normal" mothers. Similarly, $11 \%$ of children born to "very bright" mothers find themselves in the bottom decile of the behavioral problems index, compared to $6 \%$ of those born to "bright" mothers and $10 \%$ of those born to "normal" mothers (Herrnstein \& Murray, 1994, pp. 225-229).

Now since "very bright" White women marry later, and thus give birth to their babies at an older age than other mothers, perhaps some of these physical and behavioral problems of their children are attributable to their older maternal age at birth. Nonetheless, the lack of advantage of general intelligence in the area of marriage and parenting is stark in the context of Herrnstein and Murray's (1994) comprehensive survey of its undeniably clear advantage everywhere else in modern American life. This exception is so puzzling that it has led Herrnstein and Murray to muse "Can Mothers Be Too Smart for Their Own Good?" (p. 216).

This is not to argue, however, that intelligent people are not better mates or parents in general today. I'm sure intelligent individuals make better parents in some ways. One need go no farther than to recall the news story from several years ago of the

\footnotetext{
${ }^{4}$ I thank one anonymous reviewer for pointing this out to me.
} 
illiterate teenage mother whose baby died of dehydration because the mother could not read the instructions for how to make the baby formula and instead fed the formula to the baby as is, without dissolving it in water first. Note, however, that this tragedy happened precisely because it involved written instructions for making baby formula - an evolutionarily novel stimulus about an evolutionarily novel product. My contention is that even this mother would have done fine raising her children in the EEA.

My analysis of the General Social Survey (GSS; http://www .norc.uchicago.edu/projects/gensoc.asp) replicates Herrnstein and Murray's (1994) analysis of the National Longitudinal Survey of Youth. The GSS measures the verbal intelligence of its respondents by asking them to select a synonym for a word out of five candidates. Each respondent answers 10 of these questions, and their total score varies from 0 to 10 . I use the total number of correct responses as a crude measure of verbal intelligence.

Not surprisingly, this measure of verbal intelligence positively correlates with two separate achievements in evolutionarily novel domains: formal schooling and income in a capitalist economy. Table 1 shows that, controlling for age, the measure of verbal intelligence correlates .5272 with formal schooling and .1924 with income. These statistics confirm the importance of general intelligence in everyday life (Gottfredson, 1997; Herrnstein \& Murray, 1994).

In sharp contrast, intelligence does not seem to confer much advantage in the evolutionarily familiar domains of mating and parenting. The total number of children the respondent has ever had is negatively correlated with verbal intelligence $(r=-.1207$,

Table 1

The Effect of General Intelligence in Evolutionarily Novel and Familiar Domains (General Social Survey 1972-2000)

\begin{tabular}{lccr}
\hline \multicolumn{1}{c}{ Domain } & $r$ & $p$ & $n$ \\
\hline Evolutionarily novel & & & \\
$\quad$ Formal schooling & .5272 & $<.001$ & 20,188 \\
Income & .1924 & $<.001$ & 12,977 \\
Evolutionarily familiar & & & \\
$\quad$ Mating and parenting & & & \\
$\quad$ Total number of children & -.1207 & $<.001$ & 20,177 \\
Ever married & .0040 & $n s$ & 20,188 \\
Currently married & .0554 & $<.001$ & 20,188 \\
$\quad$ Controlling for income & -.0073 & $n s$ & 12,964 \\
Lifetime number of sex & .0283 & $<.05$ & 8,324 \\
$\quad$ partners & & & \\
$\quad$ Men & .0263 & $n s$ & 3,533 \\
$\quad$ Women & .0894 & $<.001$ & 4,788 \\
$\quad$ Number of sex partners & -.0378 & $<.01$ & 6,930 \\
$\quad$ in last 5 years & & & \\
$\quad$ Men & -.0261 & $n s$ & 2,974 \\
$\quad$ Women & -.0398 & $<.05$ & 3,953 \\
Number of sex partners & -.0371 & $<.001$ & 9,554 \\
$\quad$ in last 12 months & & & \\
$\quad$ Men & -.0597 & $<.001$ & 4,095 \\
$\quad$ Women & -.0052 & $n s$ & 5,456 \\
Interpersonal relations & & & \\
Friends & .0657 & $<.001$ & 14,788 \\
Neighbors & -.0278 & $<.01$ & 14,778 \\
Parents & -.0159 & $n s$ & 8,346 \\
Siblings & -.1583 & $<.001$ & 8,348 \\
Relatives & -.1023 & $<.001$ & 14,792 \\
\hline$\quad$ & & &
\end{tabular}

Note. $\quad r$ are partial correlation coefficients, controlling for age. $p<.001)$. The more intelligent they are, the fewer children they have. Since the number of children is a significant (albeit not the sole) determinant of inclusive fitness, this means that intelligent people have lower inclusive fitness than less intelligent people. This is the essence of what Vining (1986) calls the "central theoretical problem of human sociobiology" (p. 167), which I will attempt to solve below with my theory of the evolution of general intelligence.

Consistent with Herrnstein and Murray (1994), my analysis of the GSS shows that intelligent people are no more likely to get married. The partial correlation between verbal intelligence and whether they have ever been married, controlling for age, is nil $(r=.0040, n s)$. The partial correlation between verbal intelligence and whether they are currently married is small but statistically significant $(r=.0554, p<.001)$. However, even this significant correlation is spurious, produced by the fact that more intelligent people make more money and people who make more money are less likely to divorce. Once I control for income, the same partial correlation becomes nil as well $(r=-.0073, n s)$.

General intelligence does not seem to confer advantage in finding mates either. While the correlation between verbal intelligence and the lifetime number of sex partners since 18 is significantly positive, the magnitude of correlation is very small $(r=$ $.0283, p<.05)$. Further, the correlation between verbal intelligence and the number of sex partners either in the last 5 years or in the last 12 months is significantly negative $(r=-.0378, p<$ .01 , for 5 years; $r=-.0371, p<.001$, for 12 months). The more intelligent Americans are, the fewer mates they have recently had.

Now, of course, due to the asymmetry in the reproductive biology, "the number of sex partners" has a vastly different meaning for men and women (Trivers, 1972). While men can linearly increase their reproductive success with the number of women that they have sexual access to, there is no clear reproductive advantage to women for having sex with a large number of men. In this context, it is very interesting to note that it is intelligent women, not intelligent men, who acquire a large number of mates in their lifetimes. The partial correlation between verbal intelligence and the lifetime number of sex partners, controlling for age, is strongly positive among women $(r=.0894, p<.001)$ but is nonsignificant among men $(r=.0263, n s)$. It appears that intelligent men cannot use their greater intelligence to acquire more mates and increase their reproductive success and intelligent women use their intelligence to acquire more mates, when doing so does not increase their reproductive success. The former finding seems to contradict Miller's (2000) contention that general intelligence is a fitness indicator among males, at least in the context of the evolutionarily novel environment from which the GSS data come.

Both my analysis of the GSS and Herrnstein and Murray's (1994) analysis of the National Longitudinal Survey of Youth support my prediction that general intelligence is an advantage only in evolutionarily novel domains of life (such as formal schooling and income in a capitalist economy) and not in the evolutionarily familiar domains of mating, marriage, and parenting. The data are inconsistent with Cosmides and Tooby's (2002) and Chiappe and MacDonald's (2003) contention that general intelligence highly correlates with underlying domain-specific adaptations. 


\section{General Intelligence and Interpersonal Relations}

Interpersonal relations is another evolutionarily familiar domain of life. Even in the EEA, our ancestors had friends, allies, and enemies that they had to deal with. They also had parents, children, siblings, and other relatives. There is nothing evolutionarily novel about interacting with these people. Further, it was very important in the EEA (as it is now) to maintain good relations with these people. Reliable friends and allies are crucial in survival and reproductive success (de Waal, 1982), and investing in kin is a very important means of increasing inclusive fitness (Hamilton, 1964).

The GSS asks its respondents how often they spend evenings with various evolutionarily familiar categories of people (friends, neighbors, parents, siblings, and relatives) on a seven-point scale $(1=$ never to $7=$ almost daily; reverse coded $)$. Table 1 presents the correlations between verbal intelligence and the frequency of spending evenings with these categories of people. While verbal intelligence seems to confer advantage in maintaining and socializing with friends $(r=.0657, p<.001)$, it does not seem to improve interpersonal relations with other evolutionarily familiar categories of people. Verbal intelligence is significantly, and often strongly, negatively correlated with the frequency of spending evenings with neighbors $(r=-.0278, p<.01)$, siblings $(r=$ $-.1583, p<.001)$, and relatives $(r=-.1023, p<.001)$. Since, even today, 10,000 years since the end of the Pleistocene, having and investing in one's own children and investing in other members of kin are still the only ways to increase one's inclusive fitness, the analysis of the GSS presented in Table 1 collectively suggests that intelligent people are no more able, and often less able, to achieve their reproductive success than less intelligent people.

\section{Autism: The Independence of $g$ and the ToMM (Theory of Mind Module)}

Autism neatly illustrates my contention that general intelligence operates independently of all the other evolved psychological mechanisms. Even though a majority of autistic children and adults are mentally retarded, about a quarter of them are "highfunctioning" autistics within the normal IQ range (Harris, Handleman, \& Burton, 1990). ${ }^{5}$ These high-functioning autistics can therefore function as normal children and adults in most spheres of life. There's even some evidence that autistic children with IQs $1 S D$ below the mean can process information as fast as normal children with IQs $1 S D$ above the mean (Scheuffgen et al., 2000).

However, their autism does not allow them to communicate and interact with others. Despite their normal IQs, they are nonetheless "mindblind" (Baron-Cohen, 1995) and lack the theory of mind module (ToMM). The ToMM is an evolved psychological mechanism that allows individuals to attribute mental states to others and know that other people may have different information than they themselves do. For instance, if you and your friend are watching TV together but your friend steps out of the room for a few minutes, you know that your friend did not see what you just saw on TV while she was out of the room. Autistics, lacking the ToMM, do not understand this and assume that she knows everything that they do. This is the essence of what the famous "SallyAnne Test" demonstrates (Baron-Cohen, Leslie, \& Frith, 1985).
Because they have normal IQs, high-functioning autistics can comprehend reasonably well that "If P, then Q" does not logically entail "If Q, then P." Yet, they don't understand why their friend doesn't know about the funny commercial they just saw on TV while she was out of the room. This makes perfect sense from my perspective, which posits that each psychological mechanism operates independently and thus the efficiency of one ("general intelligence") has nothing to do with the efficiency of another (ToMM; see the right panel of Figure 1). Cosmides and Tooby's (2002) perspective, in contrast, cannot account for the mystery of high-functioning autistics because it stipulates a correlation between general intelligence and all underlying psychological mechanisms.

\section{The Independence of Emotional or Social Intelligence From General Intelligence}

While there is no clear definition of "emotional intelligence" (Bowman, Markham, \& Roberts, 2002, p. 140), the concept is usually taken to encompass three distinct mental processes (Salovey \& Mayer, 1990): (a) empathy (appraising and expressing emotions in the self and others), (b) self-presentation (regulating emotion in the self and others), and (c) self-regulation of mood (using emotions adaptively to achieve one's goals; Fox \& Spector, 2000, pp. 204-206). Similarly, there is no consensual definition of an even older concept of "social intelligence," but Marlowe (1986) defines it as "the ability to understand the feelings, thoughts, and behaviors of persons, including oneself, in interpersonal situations and to act appropriately upon that understanding ... . Social intelligence may therefore be equated with social competence" (p. 52).

There seems little question that what researchers variously call "emotional intelligence" or "social intelligence (or competence)" was important in the EEA. Other people and interactions with them are one thing that we are certain existed during the entire period of human evolution. Some evolutionary psychologists believe that the need to interact with (and often outsmart) others was the primary evolutionary force behind rapid encephalization (the increase in the human brain size) during the human evolutionary history (Byrne \& Whiten, 1988; Dunbar, 1996). My evolutionary psychological theory of general intelligence would therefore predict that $g$ would not increase or correlate with "emotional intelligence" or "social competence," which independently evolved to solve evolutionarily familiar tasks of interacting with others.

Fox and Spector's (2000) experiment reports the following correlations between general intelligence and various measures of emotional intelligence, the first three of which comprise Salovey,

\footnotetext{
${ }^{5}$ It is true that three quarters of autistics lacking the ToMM also have low IQs, thereby contributing to a positive correlation between general intelligence and ToMM. However, it is also true that there is an even greater number of nonautistics (with intact ToMM) with low IQs. Since autistics (both high- and low-functioning) are a very small proportion of the general population, IQ and ToMM appear to be independent in the general population as a whole. At the same time, however, it is also true that the incidence of low IQ is much higher among autistics than among nonautistics. It is therefore possible that autism has some variance in common with IQ and some independent variance. I thank one anonymous reviewer for raising this point.
} 
Mayer, Goldman, Turvey, and Palfai's (1995) Trait Meta-Mood Scale: $r=.30$, with mood repair; $r=.15$, with clarity of mood; $r=.07$, with attention to mood; $r=.07$, with perspective taking; $r=.06$, with empathic concern; and $r=-.34$, with personal distress. Only one of these correlations ( $r=.30$, with mood repair) is statistically significant at the .05 level; another $(r=-.34$, with personal distress) is even more significant $(p<.001)$ in the opposite direction! Individuals with greater general intelligence are significantly less able "to experience distress and discomfort in response to extreme distress in other people" (Fox \& Spector, 2000, p. 210).

Derksen, Kramer, and Katzko (2002) specifically explore the relationship between general intelligence and emotional intelligence among a Dutch community sample $(N=873)$. Among the entire sample, the correlation between general intelligence (General Adult Mental Ability scale) and emotional intelligence (BarOn's EQ-i), while statistically significant at .05 , is nonetheless very small $(r=.081)$. Among men $(n=489)$, the correlation is $r=.066$; among women $(n=384)$, it is $r=.095$. Neither of these correlations is statistically significant. On the basis of their data, Derksen et al. (2002) conclude that general intelligence and emotional intelligence are "psychometrically independent."

In an exploratory factor analysis of 30 measures, Davies, Stankov, and Roberts (1998) identify three factors of emotional intelligence (emotional clarity, emotional awareness, and emotional perception) and two factors of general intelligence (crystallized intelligence and fluid intelligence). None of the three factors of emotional intelligence correlates significantly with either crystallized or fluid intelligence: emotional clarity $(r=.09$, with crystallized intelligence; $r=.10$, with fluid intelligence); emotional awareness $(r=-.11$, with crystallized intelligence; $r=.00$, with fluid intelligence); and emotional perception $(r=.05$, with crystallized intelligence; $r=.15$, with fluid intelligence). Davies et al. (1998) conclude, as do Derksen et al. (2002), that "the set of skills constituting the emotional intelligence domain is conceptually distinct from other types of intelligence" (p. 999).

Marlowe and Bedell (1982) find that among 479 psychiatric patients, the correlations between social intelligence and the Shipley-Hartford abstract and verbal intelligence scores are $r=$ -.003 and $r=-.009$, respectively. Ford and Tisak (1983) find that among 620 ninth and twelfth graders, the correlations between the self-rated scores on the Social Competence Nomination Form and the verbal reasoning, numerical ability, and arithmetic reasoning subtests of the Differential Aptitude Test are $r=.14, r=.12$, and $r=.12$, respectively. None of these correlations are significant.

There seems to be sufficient evidence to conclude that measures of "emotional intelligence" or "social intelligence," which, whatever their precise definitions, would have been crucial for our ancestors' daily interactions with each other, are independent of measures of general intelligence or $g$. This is precisely what my theory of general intelligence as a domain-specific adaptation for evolutionary novelty would suggest.

\section{General Intelligence and Wayfinding}

In the hunter-gatherer life of our ancestors in the EEA, navigation and wayfinding were essential skills, on which their very survival depended. After long hunting or gathering trips, which could sometimes last for days, our ancestors had to find their way home without relying on maps, street signs, or artificial landmarks. Those who could not find their way home from their trips probably faced certain death. I would therefore expect navigation and wayfinding to be an evolutionarily familiar task, for which there is an evolved psychological mechanism, as Silverman and Eals (1992) argue, and I would predict general intelligence to be independent of wayfinding abilities.

Silverman et al. (2000) take experimental subjects on a meandering journey through a wooded area, without any visible landmarks or maps, and ask the subjects, at predetermined locations, to point to the direction of the origin. They must then lead the experimenters back to the origin. In this highly ingenious experiment, the subjects' wayfinding ability has no correlations with their general intelligence, measured by Raven's matrices test, among men $(n=46, r=-.00)$, among women $(n=60, r=$ $-.12)$, or in the total sample $(n=106, r=-.08)$.

Weiss, Morales, and Jacobs (2003) replicate Silverman et al.'s (2000) findings in virtual reality. Their subjects navigate in computer-generated "rooms" displayed on a monitor by way of a joystick and must find an invisible target placed somewhere in the room on the floor. They get a beep when they (initially unknowingly) "walk" over the invisible target and then must find it again and again in the same room by navigating to the same location in the room. Weiss et al.'s (2003) sequential canonical analysis shows that the subjects' general intelligence, measured by the Shipley Institute of Living Scales, has no effect on their ability to learn their way around the "rooms" and return to the invisible target. Consistent with my theory, Weiss et al. (2003) conclude

The present results suggest that individual differences in spatial navigation and $g$ are largely independent. This result is consistent with . . a modular view of mind, but inconsistent with the view that all mental abilities are due to a general ability underlying all mental performance. (p. 16)

\section{$g$ in Nonhuman Animals}

Finally, what would be the implications of my theory of general intelligence as a domain-specific adaptation for the concept of "animal intelligence"? What does it say about the possible existence of $g$ in nonhuman species?

Since the seminal contribution of Thorndike (1911), the field of "animal intelligence" has been dominated by behaviorists, and as a result, the concept of "animal intelligence" is usually associated with the capacity for and efficiency in learning through reinforcement contingency (Zentall, 2000). "The term 'animal intelligence,' though widely used, has become synonymous and interchangeable with the term 'animal cognition,' that is, with the investigation of specific tasks such as serial position learning or visual concept formation" (Locurto, 1997, p. 95).

What do we know about the existence of general intelligence among nonhuman species? The answer is, unfortunately, very little. In a section called "What is known about animal $g$ ?" in a chapter entitled "On the comparative generality of $g$," a strong proponent of the concept of general intelligence among nonhuman animals is forced to conclude his review of the literature with the following observation: "Nearly a century after Spearman first identified $g$ in humans, there has not been a single study that meets the technical requirements to determine whether $g$ exists in ani- 
mals" (Locurto, 1997, p. 95). Locurto (1997, pp. 91-94) argues that past empirical studies on the general intelligence of nonhuman species are deficient because the tasks that the nonhuman subjects perform (the "test batteries") are either not sufficiently varied to allow for the emergence of a general factor or not complex enough to require cognitive skills to solve.

Similarly, Jerisen (1985) declares that "there is no consensus on the nature of animal intelligence despite a century of research, though recent work on cognitive capacities of dolphins and great apes seems to be on the right track" (p. 21). Seventeen years later, the leading primatologist Byrne (2002) asserts

One cannot at the start of this enterprise be sure that intelligence is highly modular, but if it is not, nothing has been lost by studying aptitude in different domains separately. If [italics added] those separate attributes turn out to be highly correlated, one can later simplify description by invoking an underlying, general [italics added] capacity. (p. 80)

In other words, the best that one of the leading authorities on nonhuman intelligence can say at the start of the twenty-first century is "If it exists ..."

My evolutionary psychological theory can offer some suggestions as to if general intelligence exists in nonhuman species and, if so, in which species. First, in line with the general evolutionary psychological contention that there is nothing special about humans (Kanazawa, 2001, pp. 1134-1137), I predict that general intelligence is not unique to humans and can exist in other species as well. Second, since my theory holds that $g$ is a domain-specific adaptation to evolutionary novelty, I would predict that species would possess general intelligence to the extent that their environment during evolutionary history contained many novel, nonrecurrent adaptive problems. In contrast, a species should not evolve general intelligence if its environment is entirely stable and predictable.

Byrne (1995) appears to concur with me. First, his definition of general intelligence is consistent with Cosmides and Tooby's (2002) distinction between dedicated and improvisational intelligence discussed above and my definition of general intelligence as a domain-specific adaptation for evolutionary novelty.

If "intelligent" for an animal species means the same as "well adapted to the environment," then presumably all species are intelligent in their own ways! ... Animal adaptations are fascinating, but calling them "intelligence" adds nothing to our understanding. The use of the term intelligence should be restricted to that quality of flexibility that allows individuals to find their own solutions to problems; genetical adaptations, by contrast, are fixed and inflexible, however well-tuned to special environments they are. (Byrne, 1995, p. 34)

Then he goes on to predict which species might possess general intelligence.

What all these (possible) components of intelligence have in common is that they contribute to general purpose skills, not highly specialized ones ... Intelligence should most benefit extreme generalists, species adapted to exploit continually changing environments [italics added], since they must daily cope with novelty [italics added] in order to survive. Creatures adapted to unvarying environments, however intricate, would be much better off with reliable, if inflexible, methods: genetically coded strategies, or genetically channelled learning of a narrow range of information. (Byrne, 1995, p. 38)
Byrne and I thus concur that general intelligence in nonhuman animals, if it exists, should be among species that confront evolutionarily novel and nonrecurrent adaptive problems.

\section{Empirical Anomalies}

In addition to providing an evolutionary psychological explanation for the evolution of general intelligence, my theory can solve some empirical anomalies in evolutionary psychology and psychometrics. First, it can solve the so-called "central theoretical problem of human sociobiology" (Vining, 1986, p. 167): the inverse relationship between social class and reproductive success. Second, it can explain the peculiar geographical distribution of IQs throughout the world.

\section{The Central Theoretical Problem of Human Sociobiology}

Modern evolutionary psychology predicts that because women prefer to mate with men with greater resources and higher status, such men attain greater reproductive success (Buss, 1994). Throughout human history, wealthy and powerful men of high status have had a greater number of mates and produced more children than poor and powerless men of low status (Betzig, 1986). In ancient civilizations, kings, emperors, and sultans maintained large harems, consisting of hundreds and thousands of virgins, and local chiefs and noblemen kept several wives or concubines, while at the same time countless poor men in the countryside died mateless and childless (Betzig, 1993). And, these wealthy and powerful men of high status invariably left a large number of descendants.

In sharp contrast, a strong positive correlation between wealth and reproductive success does not exist in contemporary society. In the GSS data, the correlation between men's income (information on wealth is not available in the GSS) and the number of children they have ever had, after controlling for their age (which tends to increase both men's income and the number of children they have had), is significantly positive (due to a large sample size) but very weak $(r=.0236, p<.01, n=12,086)$. This observation has led some critics of evolutionary psychology to call it the "central theoretical problem of human sociobiology" (Vining, 1986, p. 167).

This theoretical problem has been solved at one level, however. Pérusse (1993) and Kanazawa (2003) demonstrate, with Canadian and American data, respectively, that wealthier men copulate more frequently and have more sex partners than less wealthy men. Evolution by natural and sexual selection equips organisms, not necessarily with the ability to attain reproductive success as the ultimate goal, but with the proximate desires and preferences to motivate behavior, which, in the context of the EEA, would have led to greater reproductive success. The desire for copulation and, in the case of males, for greater sexual variety are such proximate desires. Since there was no effective means of contraception in the EEA, other than abstinence, men who copulated more frequently and had more sex partners necessarily had more children. What appears to create the "central theoretical problem in human sociobiology" is the intervention of a cumbersome modern invention called effective contraception.

However, this solution of the problem simply leads to another question: Why is it that men with greater resources and of higher 
status use contraception more effectively than those with fewer resources and of lower status? Why do the former end up with no more children than the latter when they have more sex partners and copulate more frequently? My theory of the evolution of general intelligence as a domain-specific adaptation for novelty can provide an answer.

While mating is evolutionarily familiar, voluntary control of fertility through artificial means of contraception (such as condoms and the pill) is evolutionarily novel. In the EEA, our ancestors simply mated all the time, with pregnancy and lactation serving as the only natural means of contraception. As a result, our ancestors invariably produced a larger number of offspring than we do today, but many of them died in infancy due to infectious diseases, malnutrition, and other natural causes (including predation by humans and other animals). The average number of offspring surviving to sexual maturity in the EEA may not have been much larger than it is today. At any rate, voluntary control of fertility through artificial means of contraception was not practiced in the EEA.

This is not the case today. Since advanced industrial nations have very low infant mortality rates, if people did not practice voluntary control of fertility, they would all end up with 10 or 20 children. For the first time in human history, we cannot rely on natural means to control fertility; we have to do it ourselves. This is evolutionarily novel; thus, I would predict people with greater general intelligence to do it more effectively than those with less general intelligence. As Table 1 and numerous other studies show (Fryer, 1922; Harrell \& Harrell, 1945; Jencks, 1972, pp. 220-221; Jensen, 1980, pp. 340-341), more intelligent men attain higher status and greater resources. I believe this is why higher status men of greater resources, who are more intelligent, practice contraception more effectively and contribute to the null or inverse relationship between social class and fertility, despite their greater frequencies of copulation and larger number of mates.

\section{Geographical Distribution of General Intelligence}

In a recent book, IQ and the Wealth of Nations, Lynn and Vanhanen (2002) compile a comprehensive list of "national IQs" (the mean IQ of populations) of 185 nations in the world. One striking feature of their data is that the national IQs in sub-Saharan Africa are significantly lower than those in the rest of the world (68.8 vs. 89.1), $t(183)=15.88, p<.001$.

This, of course, makes perfect sense from my perspective of general intelligence as a domain-specific adaptation for evolutionary novelty. Since our ancestors spent most of their evolutionary history in sub-Saharan Africa, it is evolutionarily more familiar to the human brain than the rest of the world, which is more evolutionarily novel. If general intelligence evolved as a means to deal with evolutionarily novel situations, then it follows that it should evolve more rapidly in the rest of the world than in the ancestral environment of the sub-Saharan Africa.

It is important to note that the geographical differences in national IQs are not entirely explainable by the differences between the races. Largely Black nations outside of sub-Saharan Africa, mostly in the Caribbean and the South Pacific, have significantly higher national IQs than those in sub-Saharan Africa (68.8 vs. 80.5), $t(68)=10.12, p<.001$. The difference is therefore at least partly geographic, not entirely racial. This is also perfectly consistent with my theory of the evolution of general intelligence.

\section{Conclusion}

The existence and ubiquitous importance of general intelligence (the $g$ factor) poses a conundrum to evolutionary psychology and its modular view of the human mind. Cosmides and Tooby (2002) and Chiappe and MacDonald (2003) offer evolutionary psychological explanations for the evolution of domain-general intelligence as an emergent exaptation of domain-specific adaptations, which form its foundation. Their perspective would predict a correlation between the efficiency of general intelligence and that of underlying psychological mechanisms.

In contrast, I offer a different evolutionary psychological explanation for the evolution of general intelligence as a domainspecific adaptation in the sphere of evolutionary novelty. If there were a sufficient number of novel, nonrecurrent problems throughout human evolutionary history, any genetic mutation that allows its carrier to think and reason logically would have been selected for. Given the extraordinary constancy and continuity of the EEA, general intelligence in its evolutionary origin was not general at all, and its importance was limited to occasional problems that other evolved psychological mechanisms could not solve. Its universal and enormous importance today reflects the fact that we now live in an evolutionarily novel world.

Evidence presented in this article supports my contention that intelligent people are better able to solve problems only when they are evolutionarily novel, but not if they are evolutionarily familiar. The weight of the evidence seems to contradict Cosmides and Tooby's (2002) and Chiappe and MacDonald's (2003) prediction, as well as prevailing assumption among psychometricians, that intelligent people are better able to solve all types of problems. Further, my perspective can potentially solve the "central theoretical problem of human sociobiology" (Vining, 1986, p. 167) and explain the peculiar geographical distribution of general intelligence throughout the world.

My theory, like Cosmides and Tooby's (2002) and Chiappe and MacDonald's (2003), only seeks to explain the evolution of species-typical general intelligence, not individual differences in $g$. Evolutionary psychology in general cannot explain individual differences within a species and must leave them for behavior genetics to explain (Scarr, 1995; Segal \& MacDonald, 1998). My theory is therefore mute on the large number of biological correlates of $g$ between individuals, such as head and brain size and the electrochemical brain activities (Jensen \& Sinha, 1993). ${ }^{6}$

My theory is not inconsistent with these empirical findings, however. One of the possible explanations for sex differences in the brain size, for instance, is the sexual dimorphism in spatiovisual ability (Jensen, 1998, pp. 146-149). According to this view, men on average have larger brains than women (controlling for body weight), despite the fact that men do not have greater intelligence than women, because men on average have greater ability in one area (spatial visualization) than do women. If one domain-specific adaptation (spatiovisual ability) can influence the total size of the brain, it is not at all unreasonable to posit that

\footnotetext{
${ }^{6}$ I thank W. Jake Jacobs and J. Phillipe Rushton for making this point.
} 
another such adaptation (general intelligence) can influence the brain size as well as other biological phenomena in the human body.

\section{References}

Barash, D. P. (1982). Sociobiology and behavior (2nd ed.). New York: Elsevier.

Barkow, J. H., Cosmides, L., \& Tooby, J. (Eds.). (1992). The adapted mind: Evolutionary psychology and the generation of culture. New York: Oxford University Press.

Baron-Cohen, S. (1995). Mindblindness: An essay on autism and theory of mind. Cambridge, MA: MIT Press.

Baron-Cohen, S., Leslie, A., \& Frith, U. (1985). Does the autistic child have a "theory of mind"? Cognition, 21, 37-46.

Baum, W. M. (1994). Understanding behaviorism: Science, behavior, and culture. New York: HarperCollins.

Betzig, L. L. (1986). Despotism and differential reproduction: A Darwinian view of history. New York: Aldine.

Betzig, L. (1993). Sex, succession, and stratification in the first six civilizations: How powerful men reproduced, passed power on to their sons, and used power to defend their wealth, women, and children. In L. Ellis (Ed.), Social stratification and socioeconomic inequality. Vol. 1: A comparative biosocial analysis (pp. 37-74). Westport, CT: Praeger.

Bowman, D. B., Markham, P. M., \& Roberts, R. D. (2002). Expanding the frontier of human cognitive abilities: So much more than (plain) $g$ ! Learning and Individual Differences, 13, 127-158.

Buss, D. M. (1994). The evolution of desire: Strategies of human mating. New York: BasicBooks.

Buss, D. M., Haselton, M. G., Shackelford, T. K., Bleske, A. L., \& Wakefield, J. C. (1998). Adaptations, exaptations, and spandrels. American Psychologist, 53, 533-548.

Byrne, R. (1995). The thinking ape: Evolutionary origins of intelligence. Oxford, England: Oxford University Press.

Byrne, R. W. (2002). The primate origins of human intelligence. In R. J. Sternberg \& J. C. Kaufman (Eds.), The evolution of intelligence (pp. 79-95). Mahwah, NJ: Erlbaum.

Byrne, R. W., \& Whiten, A. (1988). Machiavellian intelligence: Social expertise and the evolution of intellect in monkeys, apes, and humans. Oxford, England: Oxford University Press.

Chiappe, D., \& MacDonald, K. (2003). The evolution of domain-general mechanisms in intelligence and learning. Unpublished manuscript, California State University-Long Beach.

Cosmides, L. (1989). The logic of social exchange: Has natural selection shaped how humans reason? Studies with the Wason selection task. Cognition, 31, 187-276.

Cosmides, L., \& Tooby, J. (2002). Unraveling the enigma of human intelligence: Evolutionary psychology and the multimodular mind. In R. J. Sternberg \& J. C. Kaufman (Eds.), The evolution of intelligence (pp. 145-198). Mahwah, NJ: Erlbaum.

Daly, M., \& Wilson, M. (1987). The Darwinian psychology of discriminative parental solicitude. Nebraska Symposium on Motivation, 35, 91-144.

Davies, M., Stankov, L., \& Roberts, R. D. (1998). Emotional intelligence: In search of an elusive construct. Journal of Personality and Social Psychology, 75, 989-1015.

Derksen, J., Kramer, I., \& Katzko, M. (2002). Does a self-report measure for emotional intelligence assess something different than general intelligence? Personality and Individual Differences, 32, 37-48.

DeShon, R. P., Smith, M. R., Chan, D., \& Schmitt, N. (1998). Can racial differences in cognitive test performance be reduced by presenting problems in a social context? Journal of Applied Psychology, 83, 438451.

de Waal, F. B. M. (1982). Chimpanzee politics: Power and sex among apes. London: Jonathan Cape.
Dunbar, R. I. M. (1996). Determinants of group size in primates: A general model. In W. G. Runciman, J. Maynard Smith, \& R. I. M. Dunbar (Eds.), Evolution of social behaviour in primates and man (pp. 33-57). Oxford, England: Oxford University Press.

Ford, M. E., \& Tisak, M. S. (1983). A further search for social intelligence. Journal of Educational Psychology, 75, 196-206.

Fox, S., \& Spector, P. E. (2000). Relations of emotional intelligence, practical intelligence, general intelligence, and trait affectivity with interview outcomes: It's not all just "G." Journal of Organizational Behavior, 21, 203-220.

Fryer, D. (1922). Occupational-intelligence standards. School and Society, 16, 273-277.

Geary, D. C. (2002). Principles of evolutionary educational psychology. Learning and Individual Differences, 12, 317-345.

Geary, D. C., \& Huffman, K. J. (2002). Brain and cognitive evolution: Forms of modularity and functions of mind. Psychological Bulletin, 128, 667-698.

Gordon, R. A. (1997). Everyday life as an intelligence test: Effects of intelligence and intelligence contexts. Intelligence, 24, 203-320.

Gottfredson, L. S. (1997). Why $g$ matters: The complexity of everyday life. Intelligence, 24, 79-132.

Gould, S. J. (1991). Exaptation: A crucial tool for evolutionary psychology. Journal of Social Issues, 46, 43-65.

Hamilton, W. D. (1964). The genetical evolution of social behavior. Journal of Theoretical Biology, 7, 1-52.

Harrell, T. W., \& Harrell, M. S. (1945). Army general classification test scores for civilian occupations. Educational and Psychological Measurement, 5, 229-239.

Harris, S., Handleman, J. S., \& Burton, J. L. (1990). The Stanford Binet profiles of young children with autism. Special Services in the Schools, 6, 35-143.

Herrnstein, R. J., \& Murray, C. (1994). The bell curve: Intelligence and class structure in American life. New York: Free Press.

Jencks, C. (1972). Inequality: A reassessment of the effect of family and schooling in America. New York: BasicBooks.

Jensen, A. R. (1980). Bias in mental testing. New York: Free Press.

Jensen, A. R. (1998). The g factor: The science of mental ability. Westport, CT: Praeger.

Jensen, A. R., \& Sinha, S. N. (1993). Physical correlates of human intelligence. In P. A. Vernon (Ed.), Biological approaches to the study of human intelligence (pp. 139-242). Norwood, NJ: Ablex.

Jerisen, H. J. (1985). Animal intelligence as encephalization. Philosophical Transactions of the Royal Society of London, Series B, 308, 21-35.

Kanazawa, S. (2001). De gustibus est disputandum. Social Forces, 79, 1131-1163.

Kanazawa, S. (2002). Bowling with our imaginary friends. Evolution and Human Behavior, 23, 167-171.

Kanazawa, S. (2003). Can evolutionary psychology explain reproductive behavior in the contemporary United States? Sociological Quarterly, 44, 291-302.

Kanazawa, S. (2004). The savanna principle. Managerial and Decision Economics, 25, 41-54.

Locurto, C. (1997). On the comparative generality of $g$. Advances in Cognition and Educational Practice, 4, 79-100.

Lynn, R., \& Vanhanen, T. (2002). IQ and the wealth of nations. Westport, CT: Praeger.

Marlowe, H. A., Jr. (1986). Social intelligence: Evidence for multidimensionality and construct independence. Journal of Educational Psychology, 78, 52-58.

Marlowe, H. A., \& Bedell, J. R. (1982). Social intelligence: Further evidence for the independence of the construct. Psychological Reports, $51,461-462$

Miller, G. (2000). How to keep our metatheories adaptive: Beyond Cosmides, Tooby, and Lakatos. Psychological Inquiry, 11, 42-46. 
Orians, G. H., \& Heerwagen, J. H. (1992). Evolved responses to landscapes. In J. H. Barkow, L. Cosmides, \& J. Tooby (Eds.), The adapted mind: Evolutionary psychology and the generation of culture (pp. 555579). New York: Oxford University Press.

Pérusse, D. (1993). Cultural and reproductive success in industrial societies: Testing the relationship at the proximate and ultimate levels. Behavioral and Brain Sciences, 16, 267-322.

Pinker, S. (1994). The language instinct. New York: Morrow.

Salovey, P., \& Mayer, J. D. (1990). Emotional intelligence. Imagination, Cognition and Personality, 9, 557-568.

Salovey, P., Mayer, J. D., Goldman, S. L., Turvey, C., \& Palfai, T. P. (1995). Emotional attention, clarity, and repair: Exploring emotional intelligence using the Trait Meta-Mood Scale. In J. Pennebaker (Ed.), Emotion, disclosure, and health (pp. 125-154). Washington, DC: American Psychological Association.

Scarr, S. (1995). Psychology will be truly evolutionary when behavior genetics is included. Psychological Inquiry, 6, 68-71.

Scheuffgen, K., Happé, F., Anderson, M., \& Frith, U. (2000). High "intelligence," low "IQ"? Speed of processing and measured IQ in children with autism. Development and Psychopathology, 12, 83-90.

Segal, N. L., \& MacDonald, K. B. (1998). Behavioral genetics and evolutionary psychology: Unified perspective on personality research. $\mathrm{Hu}$ man Biology, 70, 159-184.

Silverman, I., Choi, J., Mackewn, A., Fisher, M., Moro, J., \& Olshansky, E. (2000). Evolved mechanisms underlying wayfinding: Further studies on the hunter-gatherer theory of spatial sex differences. Evolution and Human Behavior, 21, 201-213.

Silverman, I., \& Eals, M. (1992). Sex differences in spatial abilities:
Evolutionary theory and data. In J. Barkow, L. Cosmides, \& J. Tooby (Eds.), The adapted mind: Evolutionary psychology and the generation of culture (pp. 533-549). New York: Oxford University Press.

Stanovich, K. E., \& West, R. F. (2000). Individual differences in reasoning: Implications for the rationality debate? Behavioral and Brain Sciences, $23,645-726$.

Thorndike, E. L. (1911). Animal intelligence: Experimental studies. New York: Macmillan.

Trivers, R. L. (1972). Parental investment and sexual selection. In B. Campbell (Ed.), Sexual selection and the descent of man 1871-1971 (pp. 136-179). Chicago: Aldine.

Vining, D. R., Jr. (1986). Social versus reproductive success: The central theoretical problem of human sociobiology. Behavioral and Brain Sciences, 9, 167-216.

Weiss, A., Morales, A., \& Jacobs, W. J. (2003). Place learning in virtual space IV: Spatial navigation and general intelligence appear independent. Unpublished manuscript, University of Arizona.

Yamagishi, T., Tanida, S., Mashima, R., Shimoma, E., \& Kanazawa, S. (2003). You can judge a book by its cover: Evidence that cheaters may look different from cooperators. Evolution and Human Behavior, 24, 290-301.

Zentall, T. R. (2000). Animal intelligence. In R. J. Sternberg (Ed.), Handbook of intelligence (pp. 197-215). Cambridge, England: Cambridge University Press.

Received November 22, 2002

Revision received September 15, 2003

Accepted September 21, 2003

\section{ORDERFORM}

Start my 2004 subscription to Psychological Review!

ISSN: $0033-295 \mathrm{X}$

\$63.00, APA Member/AfFiliate
$\$ 129.00$, Individual Nonmember
$\$ 330.00$, InstituTion
In $D C$ add $5.75 \% /$ In MD add $5 \%$ sales tax
Total AMOUNT ENCLOSED $\$$

Subscription orders must be prepaid. (Subscriptions are on a calendar basis only.) Allow 4-6 weeks for delivery of the first issue. Call for international subscription rates.



SEND THIS ORDER FORM TO:

American Psychological Association

Subscriptions

750 First Street, NE

Washington, DC 20002-4242

Or call (800) 374-2721, fax (202) 336-5568.

TDD/TTY (202) 336-6123.

For subscription information, e-mail: subscriptions@apa.org
Send me a FREE Sample Issue

Check enclosed (make payable to APA)

charge my: OVISA OMasterCard OAmerican Express

Cardholder Name

Card No. Exp. Date

BILLING ADDRESS:

Signature (Required for Charge)

City

State Zip

Daytime Phone

E-mail

SHIP TO:

Name

Address

City

State

Zip

APA Member \# REVAI 